2017-05-10

\title{
It's No Accident: Evaluating the Effectiveness of Vehicle Safety Inspections
}

\author{
Alex Hoagland \\ Brigham Young University - Provo, alexhoagland16@gmail.com \\ Trevor Woolley \\ Brigham Young University - Provo
}

Follow this and additional works at: https://scholarsarchive.byu.edu/fhssconference_studentpub

Part of the Automotive Engineering Commons, Economics Commons, and the Urban Studies and Planning Commons

The Annual Mary Lou Fulton Mentored Research Conference showcases some of the best student research from the College of Family, Home, and Social Sciences. The mentored learning program encourages undergraduate students to participate in hands-on and practical research under the direction of a faculty member. Students create these posters as an aide in presenting the results of their research to the public, faculty, and their peers.

\section{BYU ScholarsArchive Citation}

Hoagland, Alex and Woolley, Trevor, "It's No Accident: Evaluating the Effectiveness of Vehicle Safety Inspections" (2017). FHSS Mentored Research Conference. 318.

https://scholarsarchive.byu.edu/fhssconference_studentpub/318

This Poster is brought to you for free and open access by the Family, Home, and Social Sciences at BYU ScholarsArchive. It has been accepted for inclusion in FHSS Mentored Research Conference by an authorized administrator of BYU ScholarsArchive. For more information, please contact scholarsarchive@byu.edu, ellen_amatangelo@byu.edu. 


\section{It's No Accident: Evaluating the Effectiveness of Vehicle Safety Inspections}

\section{Background}

- Traffic fatalities have fallen steadily over the past two decades, particularly those due to car failure. Many have attributed this fall to safer vehicle technology.

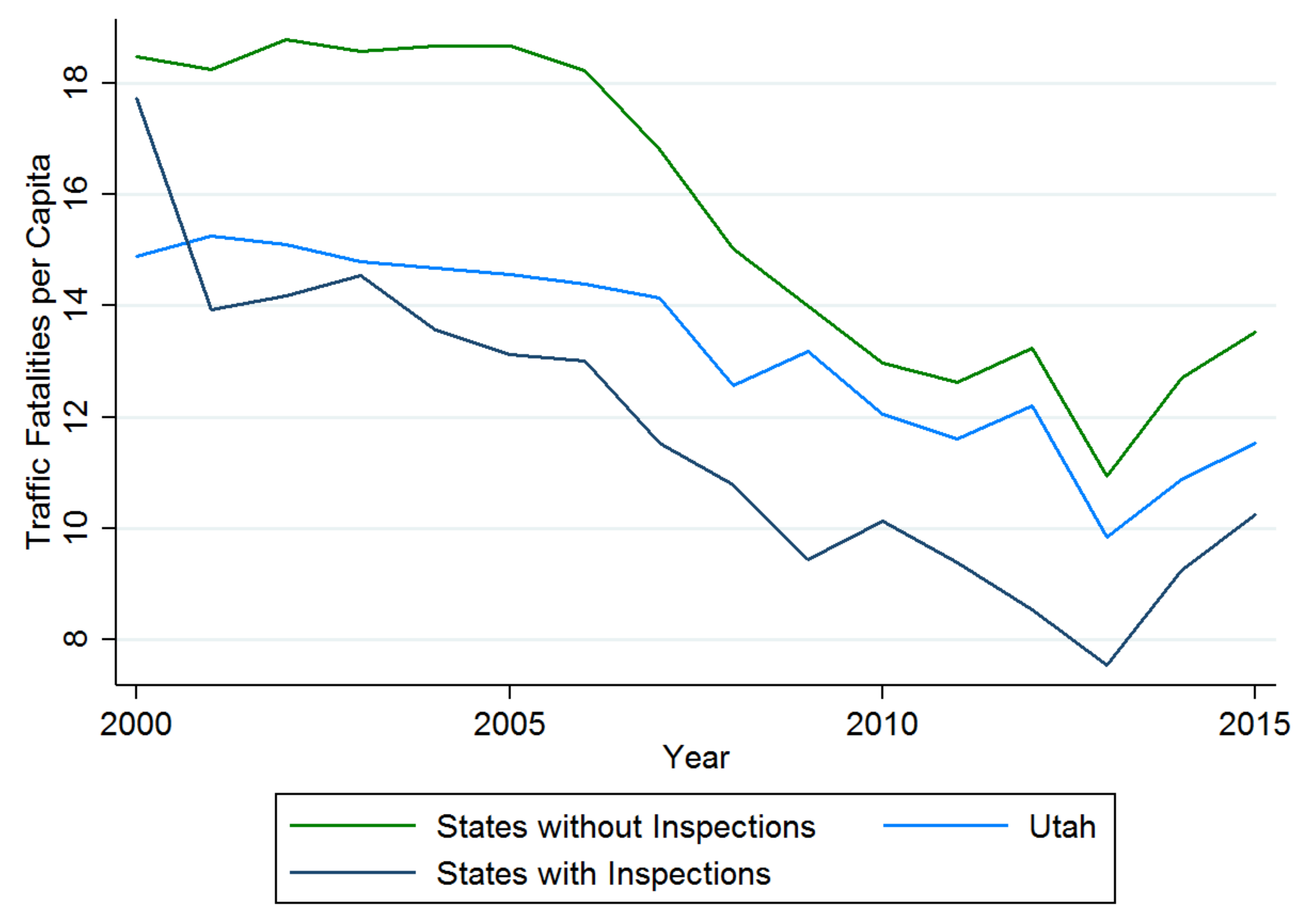

- This trend has led many states to reevaluate mandatory vehicle safety inspection programs. In 2009 and 20IO, New Jersey and Washington, D.C. ended their programs, opening a perfect window for analysis.

- At the time our project began, I6 states still required periodic inspections.

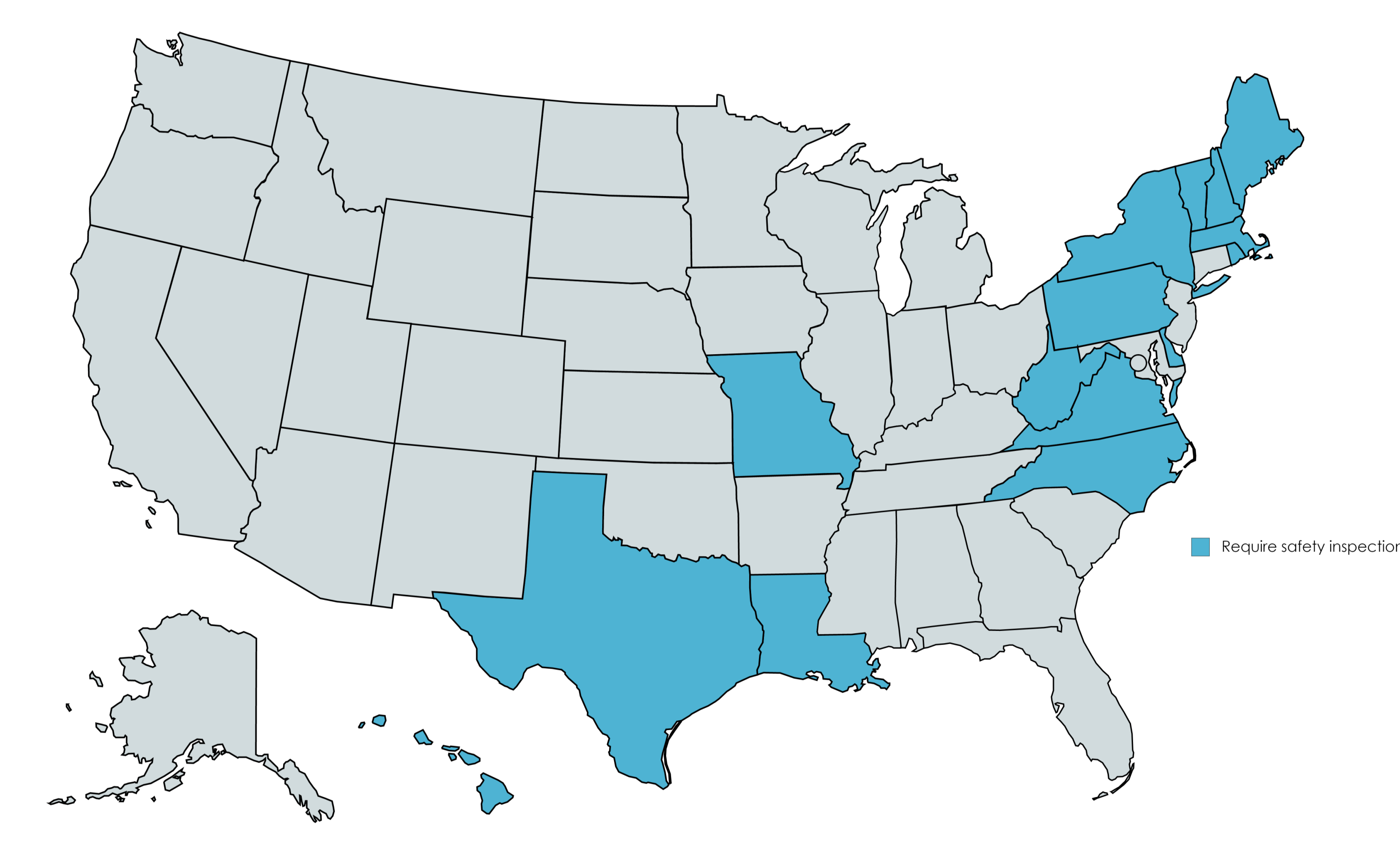

Does the elimination of vehicle safety inspections have an effect on traffic fatalities?

\section{Methodology}

- Data are from the NHTSA Fatality Analysis Reporting System (FARS), from 2000 to 20 I5. These data allow us to isolate fatality rates due specifically to car failure across the country, and to look at the state registration of vehicles involved in a crash.

- We use synthetic controls to construct a viable counterfactual explaining how traffic fatalities due to car failure in New Jersey and Washington D.C. might have unfolded without the change in policy.

- The counterfactual is constructed using a convex combination of states with inspections, assigning weights in order to match the control and treatment groups on pre-intervention trends. We matched our control to our treatment groups on the conditions of driver, vehicle, and accident demographics, as well as weather/light conditions and accidents related to drugs, alcohol, speeding, and distracted driving.

\begin{tabular}{lc}
\hline Weight given to: & Synthetic New Jersey \\
\hline Georgia & \\
Maryland & 0.091 \\
New York & 0.185 \\
South Carolina & 0.573 \\
Texas & 0.005 \\
Virginia & 0.040 \\
& 0.106
\end{tabular}

\section{Findings}

- Differences between the synthetic control group and treatment group are small, and do not differ across the intervention period.
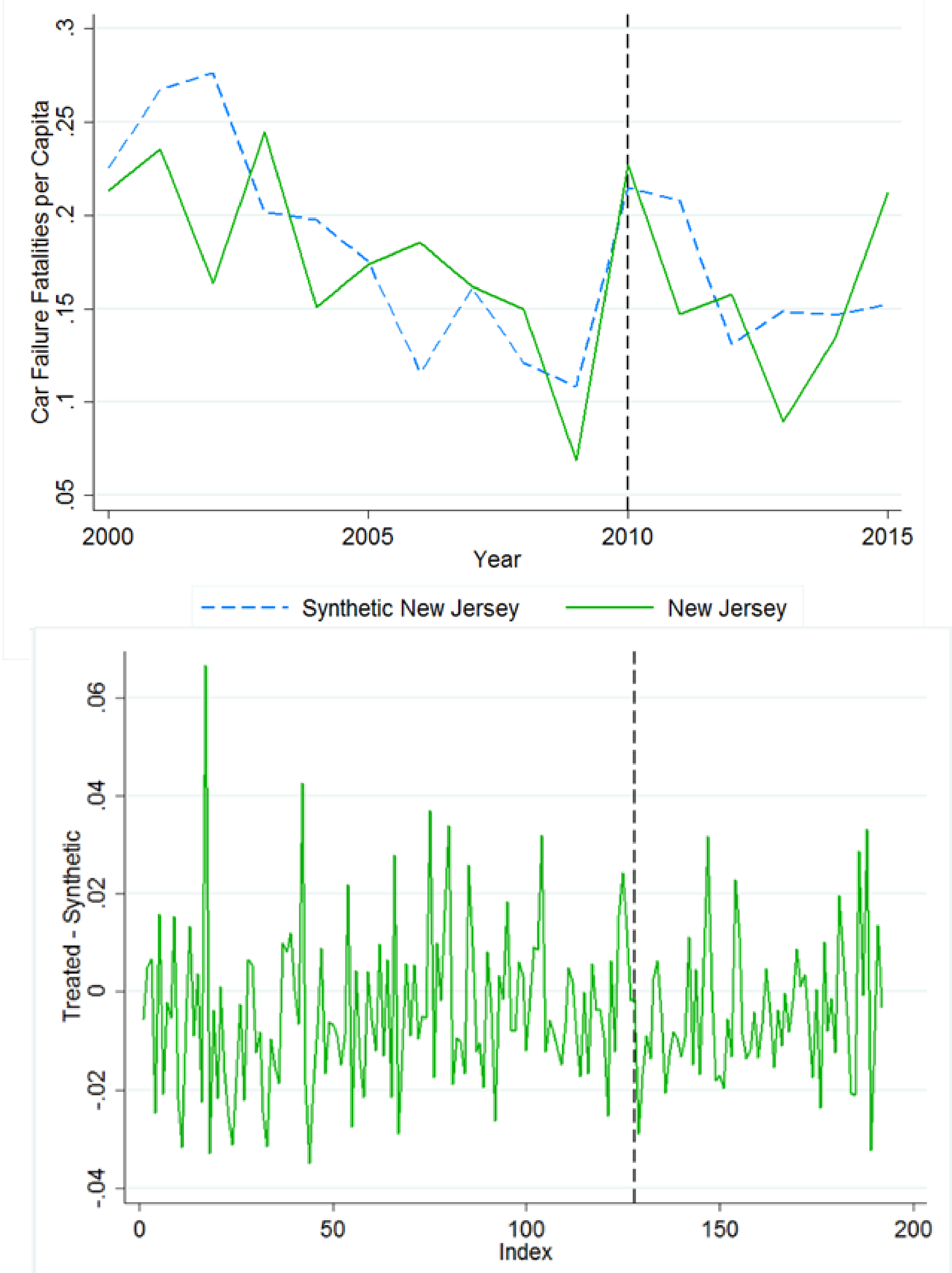

\section{Verification}

- To verify the significance of these results, we run placebo tests, in which we randomly assign I of I6 states requiring vehicle inspections to undergo a "fake repeal" in 2009. By comparing the differences between our synthetic control group and placebo treatment groups, we identify that the differences seen in our actual treatment groups (New Jersey and Washington, D.C.) are small and insignificant.

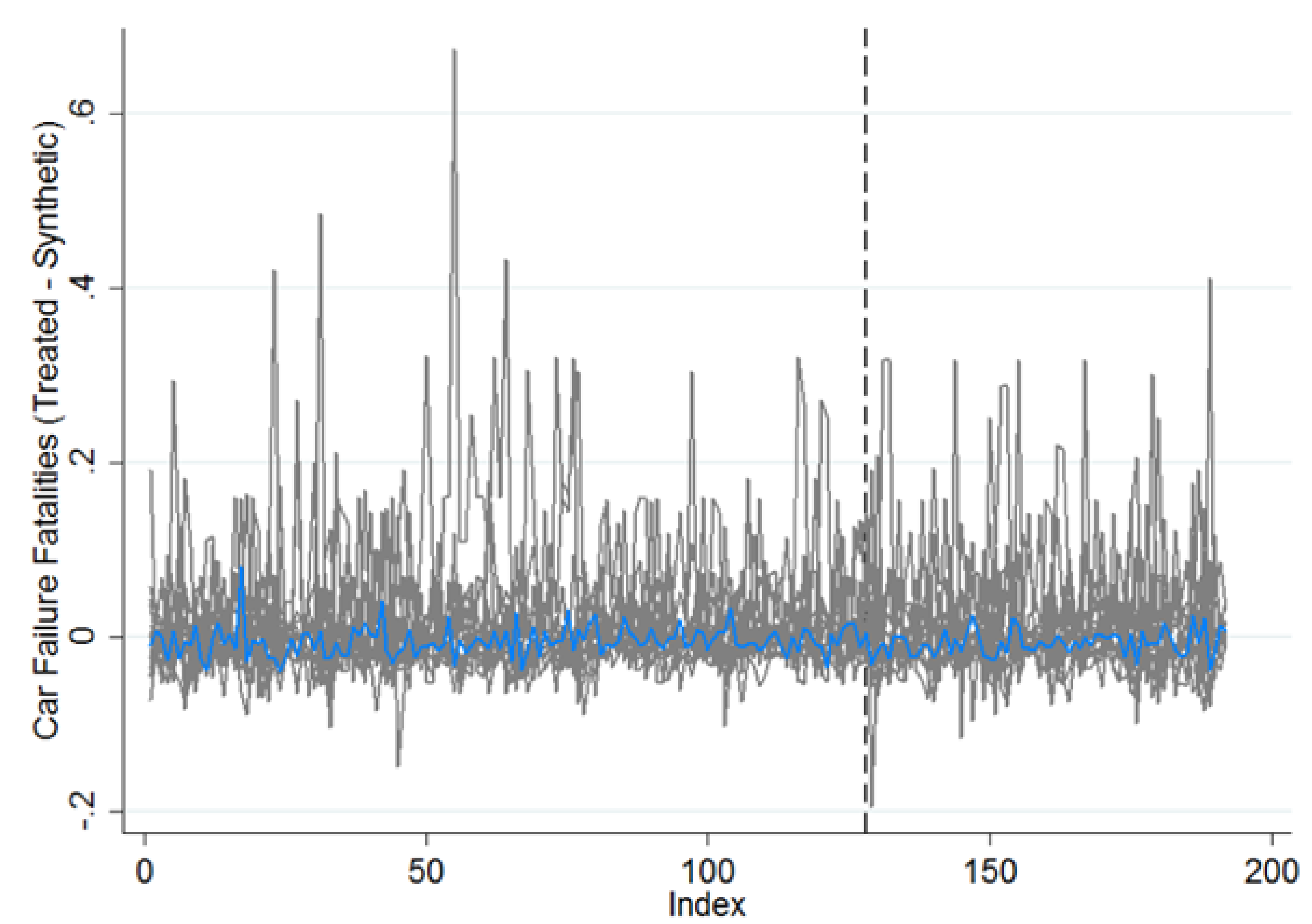

- Terminating the vehicle safety inspection program resulted in no significant change in either the frequency or intensity of fatalities due to car failure.

- As a robustness check, we used difference-in-difference analysis iteratively with different neighboring states as controls. This does not change our findings.: in all iterations, there were no significant effects to eliminating inspection programs.

\begin{tabular}{|c|c|c|c|c|c|c|}
\hline $\begin{array}{l}\text { New Jersey } \\
\text { Dependent } \\
\text { Varaibles }\end{array}$ & $\begin{array}{l}\text { Hof Car } \\
\text { Failure } \\
\text { Fatallities }\end{array}$ & 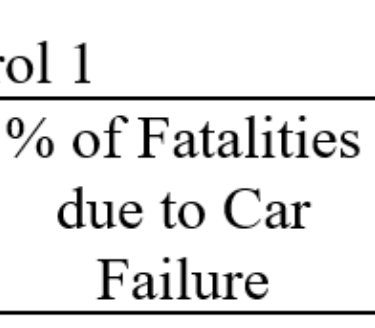 & $\begin{array}{l}\text { \#pofCar } \\
\text { Failure } \\
\text { Fatalitites }\end{array}$ & 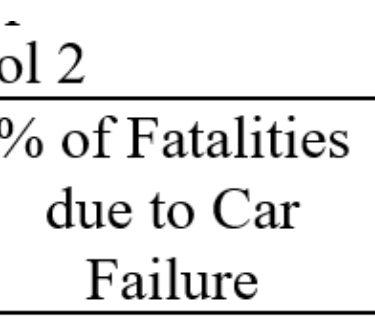 & 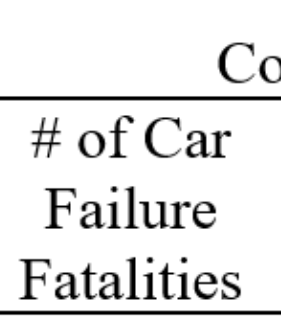 & 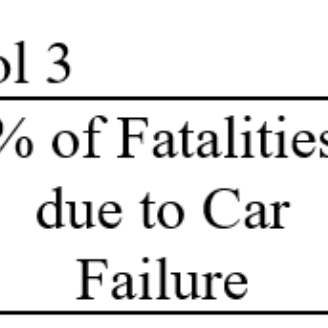 \\
\hline New Jersey & $-0.014 *$ & $-0.013^{*}$ & & $0.004^{* * *}$ & & \\
\hline I aw Chano & $(0.008)$ & $\left(\begin{array}{c}0.007) \\
0007\end{array}\right)$ & $\begin{array}{l}(0.003) \\
0.013 * * *\end{array}$ & $\begin{array}{l}(0.002) \\
0.018 * 2 * *\end{array}$ & $\left(\begin{array}{l}0.001) \\
0003\end{array}\right.$ & $\begin{array}{l}(0.001) \\
0.009 * * * *\end{array}$ \\
\hline & $\begin{array}{l}-0.003 \\
(0.009)\end{array}$ & $\begin{array}{l}0.007 \\
(0.009)\end{array}$ & $\begin{array}{l}0.013 * * * * \\
(0.004)\end{array}$ & 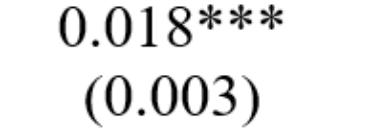 & $\begin{array}{l}0.003 \\
(0.002)\end{array}$ & $\begin{array}{l}0.009{ }^{0.002} \\
(0.02\end{array}$ \\
\hline 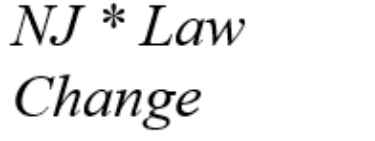 & $\begin{array}{l}0.003 \\
(0.010)\end{array}$ & $\begin{array}{l}0.001 \\
(0.009)\end{array}$ & $\begin{array}{l}-0.011+04 * 4 * \\
(0.004)\end{array}$ & 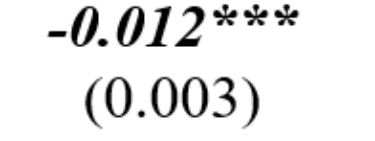 & $\begin{array}{l}-0.004 \\
(0.003)\end{array}$ & $\begin{array}{l}-0.003 \\
(0.002)\end{array}$ \\
\hline $\begin{array}{l}\text { Observations } \\
\text { Ds }\end{array}$ & 374 & 374 & 748 & ${ }^{748}$ & 1,122 & $\begin{array}{l}1,122 \\
0,227\end{array}$ \\
\hline
\end{tabular}

\section{Implications}

- This finding strongly suggests that vehicle safety inspection programs are no longer necessary, and are simply a form of residual government oversight.

- Government attention to other areas (e.g. distracted driving laws, seat belt enforcement, etc.) is more efficient than safety inspections at ensuring road safety. - In the 2017 legislative session, the Utah State Legislature voted to end Utah's vehicle safety inspection program as a result of this research. Texas and Mississippi are considering similar proposals in their sessions. 